\title{
POSSIBLE ROLES OF ACTIN AND MYOSIN DURING ANAPHASE CHROMOSOME MOVEMENTS IN LOCUST SPERMATOCYTES
}

Lacramioara Fabian and Arthur Forer*

Biology Department, York University

4700 Keele Street, Toronto, Ontario, M3J 1P3, Canada

* Corresponding author: aforer@yorku.ca

Running title: L. Fabian and A. Forer: Chromosome movements in locust spermatocytes 


\section{SUMMARY}

We tested whether the mechanisms of chromosome movement during anaphase in locust [Locusta migratoria (L.)] spermatocytes might be similar to those described in cranefly spermatocytes. Actin and myosin have been implicated in anaphase chromosome movements in crane-fly spermatocytes as indicated by effects of inhibitors and by localisations of actin and myosin in spindles. In this study we tested whether locust spermatocytes spindles also utilize actin and myosin and whether actin is involved in microtubule flux. Living locust spermatocytes were treated with inhibitors of actin (Latrunculin B and Cytochalasin D), an inhibitor of myosin (BDM), or inhibitors of myosin phosphorylation (Y-27632 and ML-7). We added drugs (individually) during anaphase. Actin inhibitors alter anaphase: chromosomes either completely stop moving, slow, or sometimes accelerate. The myosin inhibitor, BDM, also alters anaphase: in most cases, the chromosomes drastically slow or stop. ML-7, an inhibitor of MLCK, causes chromosomes to stop, slow, or sometimes accelerate, similar to actin inhibitors. Y27632, an inhibitor of Rho-kinase, drastically slows or stops anaphase chromosome movements. The effects of the drugs on anaphase movement are reversible: most of the half-bivalents resume movement at normal speed after these drugs are washed out. Actin and myosin were present in the spindles in locations consistent with their possible involvement in force production. Microtubule flux along kinetochore fibres is an actin-dependent process, since LatB removes completely or drastically reduces the gap in microtubule acetylation at the kinetochore. These results suggest that actin and myosin are involved in anaphase chromosome movements in locust spermatocytes. 


\section{INTRODUCTION}

Nuclear division (karyokinesis or mitosis) includes reorganization of different cell structures. As cell division begins, a bipolar spindle forms that ensures accurate segregation of the condensed chromosomes between daughter cells during anaphase. Most models proposed for chromosome movement consider anaphase as a microtubule-based mechanism, in which spindle microtubules and their motors are the key, if not the only, spindle components involved in the functioning of the spindle (reviewed in McIntosh et al. 2002) and in producing tubulin flux in kinetochore microtubules (Sawin and Mitchison 1991). Some models describe anaphase as an actin-based mechanism, in which actin and myosin are involved in chromosome movement (Forer and Pickett-Heaps 1998; Silverman-Gavrila and Forer 2001; Silverman-Gavrila and Forer 2003) and work together in a spindle matrix (Fabian et al. 2006).

Actin and myosin have been found in a variety of spindles (Table I of Forer et al. 2003; Margolin 2005) and various functional tests using inhibitors indicate that actin and myosin are needed for attachment of prometaphase chromosomes to the spindle in crane-fly spermatocytes (Forer and Pickett-Heaps 1998; Silverman-Gavrila and Forer 2000), in PtK cells (Sanger et al. 1989), and in algae (Sampson et al. 1996) and that actin and myosin are required for anaphase movements in these and other systems (Schmit and Lambert 1990; LaFountain et al. 1992; Sampson et al. 1996; Forer and Pickett-Heaps 1998; SilvermanGavrila and Forer 2001; Margolin 2005). Treatments of crane-fly spermatocytes in anaphase with anti-actin or anti-myosin inhibitors generally cause slowing or stopping of movements of partner half-bivalents, though sometimes they have no effect (Silverman-Gavrila and Forer 2001; Fabian and Forer 2005); often the chromosomes recover in the continued presence of the drug. While these data implicate actin and myosin in anaphase chromosome movement, 
other components also may be utilised, since movements are normal in actin-free spindles formed by removing actin in prometaphase and keeping cells continuously in an anti-actin drug (Fabian and Forer 2005). Thus redundant mechanisms may be present and available to move chromosomes during anaphase.

The localisations of various cytoskeletal proteins in spindles also suggest functional roles for actin and myosin. Confocal microscope studies on crane-fly spermatocytes, using immunocytochemistry, indicate that actin and myosin are located in spindles in positions where they would be expected to be, were they involved in force production (SilvermanGavrila and Forer 2003). Another muscle protein, titin, responsible for muscle's elasticity, also is present in crane-fly spermatocytes (Fabian et al. 2006), in association with the matrix proteins skeletor (Walker et al. 2000), megator (Qi et al. 2004) and chromator (Rath et al. 2004), consistent with the involvement of all these proteins with a spindle matrix (Fabian et al. 2006)

Actin and myosin also are required for flux of tubulin within kinetochore microtubules in crane-fly spermatocytes (Silverman-Gavrila and Forer 2000). Flux, a steady poleward movement of tubulin subunits in the kinetochore microtubules (Sawin and Mitchison 1991), is due to incorporation of tubulin at the kinetochore (polymerization) coupled to depolymerization of the microtubules at their minus ends at the pole (Mitchison 1989; Maddox et al. 2003). Flux of tubulin is considered to be important for poleward movement of chromosomes during anaphase (reviewed in Rogers et al. 2005). Usually, flux is measured after intracellular injection of fluorescent tubulin or photoactivable tubulin [e.g. Mitchison (1989); LaFountain et al. (2004)]. Other methods also have been used, e.g., staining with antibodies against total tubulin and against acetylated (stable) tubulin, respectively (Wilson et 
al. 1994; Wilson and Forer 1997). Kinetochore microtubules are more stable than the polar microtubules (discussed in Wilson and Forer 1989) and these stable microtubules are acetylated (Palazzo et al. 2003). Antibody against acetylated tubulin demonstrated acetylation only in the kinetochore microtubules; a "gap in acetylation" at the kinetochore (Wilson and Forer 1989) represents newly incorporated tubulin that has not had time to be acetylated. Thus, the gap is a measure of tubulin flux along kinetochore microtubules (Wilson et al. 1994; Wilson and Forer 1997). We studied flux in locust spermatocytes by measuring the gap in acetylation of tubulin at the kinetochore.

Most of the studies implicating actin and myosin in anaphase movements are from crane-fly spermatocytes, which are unique in many ways. For example, sex chromosomes have fibres to both poles; they enter anaphase only after the autosomes reach the poles (Forer 1969); and there are signals between sex chromosomes (Ilagan and Forer 1997), between partner autosomes (Wong and Forer 2003), and between autosomes and sex chromosomes (Sillers and Forer, 1981). Thus we studied locust spermatocytes to see how general were the conclusions drawn from crane-fly spermatocytes. Locusts were available to us and, in many aspects of division, locust spermatocytes are similar to the better studied grasshopper spermatocytes, which have been used for a variety of experiments related to chromosome orientation in the spindle (Ault 1986; 1984; Rebollo and Arana 1995), microtubule attachment and role of tension in checkpoint signals (Nicklas et al. 2001), and anaphase movements of chromosomes (Ris 1949; Ault and Nicklas 1989; Paliulis and Nicklas 2000; Chen and Zhang 2004). We are aware of only few papers that describe locust (Locusta) spermatocytes. McClung (1902) and Mohr (1914) gave detailed descriptions of stages of division in spermatocytes of Locustidae based on fixed and stained preparations; Rees and Jamieson 
(1954) described the supernumerary chromosome in Locusta; Moens (1969) described the fine structure of meiotic chromosome polarization and pairing in Locusta spermatocytes; White (1935) studied the effects of X-rays on mitosis in Locusta. Gawadi (1974), using electron micrographs, showed that actin filaments are present in locust spermatocytes spindles, that these filaments are parallel with the microtubules, and that they attach occasionally to the chromosomes, most of them with the pointed end facing the equator. Other studies showed that intracellular $\mathrm{Ca}^{2+}$ might have a role in controlling anaphase movements in locust spermatocytes by regulating microtubule assembly/disassembly, activation of actin filaments or stimulation of a dynein-like ATPase (Beier and Hauser 1981). The role of actin in anaphase chromosome movements in locust spermatocytes was emphasized by studies using inhibitors (vanadate and taxol) which disrupt the spindle framework (Daub and Hauser 1986; 1988); these studies also support the model that consider microtubules as not the force-producers in anaphase, but rather as the rate-limiting factor in anaphase motion, as originally proposed by Forer (1974). Since there have been few detailed descriptions of living spermatocytes, part of our study is a basic description of meiosis in living locust spermatocytes.

In addition to studying live control cells, we localised actin, myosin and other potentially functional proteins in spindles of locust spermatocytes, and we used actin inhibitors Cytochalasin D (CD) and latrunculin B (LatB), myosin inhibitor 2,3-butanedione monoxime (BDM) and inhibitors of myosin phosphorylation (Y-27632 and ML-7) to test their involvement in anaphase chromosome movements and to test if actin is required for the flux of tubulin in kinetochore microtubules. We report the results in this article. 


\section{MATERIALS AND METHODS}

Male $5^{\text {th }}$ instar locusts were dissected under Halocarbon oil 200 (Halocarbon Products

Corp. NY, USA) and testes were removed and put onto well slides under oil to prevent evaporation. Individual lobes were removed from the testis, rinsed with Belar's Ringers solution (Belar 1929), and placed in a fibrin clot in a perfusion chamber, following procedures similar to those used for crane flies (Fabian and Forer 2005; Forer and Pickett-Heaps 2005).

Living locust spermatocytes in perfusion chambers were kept in Belar's Ringers solution (Belar 1929) or treated at various times, as given in the text, with different inhibitors $(1.5 \mu \mathrm{M}$ or $2 \mu \mathrm{M}$ LatrunculinB; $20 \mathrm{mM}$ BDM; $20 \mu \mathrm{M}$ or $30 \mu \mathrm{M}$ CytochalasinD; $50 \mu \mathrm{M} \mathrm{Y}-27632$; $75 \mu \mathrm{M}$ ML-7). Y-27632 and BDM were diluted $\sim 1000 \mathrm{x}$ from stock solutions made up in Ringers solution; Latrunculin B, cytochalasin D and ML-7 were diluted $\sim 1000 \mathrm{x}$ from stock solutions made up in dimethylsulphoxide (DMSO). DMSO at its final concentration of $0.1 \%$ has no effect on locust spermatocytes (e.g., Daub and Hauser, 1988), similar to the lack of effect of DMSO on crane-fly spermatocytes (e.g., Forer and Pickett-Heaps, 1998, at 0.2\% DMSO, and LaFountain et al., 1992, at 1\% DMSO) or on PtK cells (Wrench and Snyder, 2001, at $0.4 \%$ DMSO). The perfusion of Ringers solution itself had no effect on locust spermatocyte division either, similar to results in crane-fly spermatocytes (Forer and PickettHeaps, 1998).

Images of live cells, taken using phase-contrast microscopy (Nikon oil immersion 100x objective, NA=1.3), were recorded on VHS tapes or directly on DVDs. Time-lapsed images were obtained from VHS sequences using Adobe Premiere and from the real-time sequences on DVDs using Virtual Dub (http://fcchandler.home.comcast.net). Chromosome velocities were calculated using custom software and data were plotted using SlideWrite. 
For immunostaining we followed the protocol described in detail in (Fabian and Forer 2005). We used the following solutions: $2.2 \mathrm{M}$ Alexa 488 phalloidin for filamentous actin (Molecular Probes), 1:200 My21 mouse IgM antibody against myosin regulatory light chain (Sigma), 1:4000 YL1/2 rat antibody against tyrosinated tubulin (Kilmartin et al. 1982), 1:200 6-11B-1 mouse antibody against acetylated tubulin (Sigma), 1:500 mouse antibody against $\alpha$ tubulin (Cedarlane), 1:500 -KZ rat antibody against D-Titin-KZ (Machado et al. 1998), 1:100 mAb1A1 mouse IgM antibody against skeletor (Walker et al. 2000), 1:100 6H11 mouse antibody against chromator (Rath et al. 2004) and 1:100 12F10 mouse antibody against megator (Qi et al. 2004). The flourochromes we used were Alexa 488, Alexa 568 or Alexa 594 (Molecular Probes) conjugated with the appropriate secondary antibodies. Images were obtained using an Olympus Fluoview 300 confocal microscope and were further processed using Image J (http://rsb.info.nih.gov/ij/) and Adobe Photoshop software. 


\section{RESULTS}

\section{Control cells}

Locust meiosis-I spermatocytes contain 11 pairs of telocentric autosomes of variable size and one large univalent sex chromosome which does not align at the equator during metaphase but stays near one pole (Fig. 1) (McClung 1902; Rees and Jamieson 1954; John and Hewitt 1966). Prometaphase lasts for at least 120 minutes (at $20-25^{\circ} \mathrm{C}$ ), the longest we followed some of the cells. During prometaphase, the chromosomes move up and down in the spindle, with variable speeds. Prometaphase ends when the autosomes are arranged in a metaphase plate, where they continually adjust their positions through small movements, toward and away from the poles. The bigger autosomes are generally arranged at the exterior of the spindle, while the smaller ones are in the middle of the spindle. Metaphase lasts on average 10 minutes (7-12 minutes), after which all autosomes enter anaphase at the same time and move with average constant separation velocities of $1.2 \mu \mathrm{m} / \mathrm{min}$ (Table I), as calculated from graphs of interkinetochore distance versus time for individual pairs of separating halfbivalents (Fig. 2). The different pairs of chromosomes reach the poles at about the same time, but because the interkinetochore distances at the start of anaphase are different and because those in the middle of the spindle travel different distances than those on the outside of the spindle, the speeds of the different pairs in the cell vary somewhat. For all pairs, however, during the first part of the anaphase the pole-to-pole distance remains constant. After the halfbivalents reach the poles the spindle elongates, as described for locust spermatocytes previously by Beier and Hauser (1981). Because different chromosomes are in different focal planes, we could not follow all of the 11 pairs of chromosomes at the same time. We followed in detail only those in the plane of focus that we recorded, which limited us to 3-4 separating 
pairs per spermatocyte. Each set of points in our graphs is of one pair of separating halfbivalents, but we always followed more than that, invariably 3-4 pairs per cell.

Anaphase $\mathrm{A}$ is about 10 minutes long (range from 6-22 $\mathrm{min}$ ), from the moment the bivalents disjoin until they reach the poles. Locust primary spermatocytes have a $20-24 \mu \mathrm{m}$ long spindle (when flattened), while secondary spermatocytes have a sightly shorter spindle $(16-20 \mu \mathrm{m})$. Though we did not follow primary spermatocytes after cleavage, meiosis-II is reported to occur very rapidly after the meiosis-I with practically no interkinesis (White 1935). The spindle is outlined by mitochondria, which are distributed on both sides of the spindle during the first division (Fig. 1), but only on one side during the second division.

\section{Actin and myosin are present in locust spermatocytes.}

Actin filaments in locust spermatocytes were first described in electron micrographs by Gawadi $(1971 ; 1974)$. General spindle staining using immunofluorescence and actin antibodies was seen in non-treated locust spermatocytes by Beier and Hauser (1981). Our confocal microscope studies showed that actin is present both in the cortex and in the spindle during prometaphase, metaphase and anaphase (Fig. 3), but actin is organized differently in locust spindles compared to crane-fly spindles. Actin in locust spindles is distributed in short filaments, in short stretches of actin, in a finely dispersed mass of punctate actin, associated with kinetochore and other microtubules, forming a compact (but weak) actin "area" in the spindle. The spindle is surrounded by many short actin filaments, forming a "spindle cage", which is distinct from the cortex. From place to place, this cage seems to send longer filaments of actin to the cortex, as if anchoring the spindle to the cortex (Fig. 3). The "caged" locust spindles seem similar to those described in many plant cells (e.g., Schmit and Lambert 1988, 1990; review in Staiger and Schliwa 1987). Actin co-localizes with tubulin along the 
spindle fibres (Fig. 3). Myosin is present in the spindle and around the chromosomes, in a punctate pattern, co-localized with tubulin along the kinetochore fibres (Fig. 3), as well as along polar microtubules and outside the microtubule fibres.

Several other proteins are present in the spindles of locust spermatocytes in addition to actin and myosin. In other work we have described in detail the distributions of titin, a muscle protein, and of several matrix proteins (skeletor, megator, chromator) (Walker et al. 2000; Qi et al. 2004; Rath et al. 2004) in locust spermatocytes (Fabian et al. 2006); here, for completeness, we briefly review their distribution. Titin is present in the spindle, in the chromosomes, at the poles, and in a punctate distribution along kinetochore fibres (Fig. 4). Skeletor is present in the spindle and at the poles; it co-localizes with tubulin along spindle fibres (Fig. 4). Megator and chromator have a dotted appearance and they are closely associated with microtubules, during all phases of division (Fig. 4). They are present in the chromosomes, in the nuclear membrane, in the spindle, along all microtubules (kinetochore, polar, astral microtubules), in the midbody, but not in the contractile ring. Megator, chromator and titin are closely associated with actin and myosin in chromosomes, at the poles, and along non-kinetochore and kinetochore microtubules, but they are organized differently and do not always co-localize (Fabian et al., 2006). Thus, these muscle and matrix proteins are present in locust spermatocytes in locations in which they could be involved in chromosome movement, perhaps functioning together in a contractile spindle matrix (Fabian et al. 2006).

After studying localisation of actin, myosin and associated proteins in locust spindles, we studied the physiological roles of actin and myosin in these spermatocytes by using various actin and myosin inhibitors. 


\section{Effects of myosin inhibitors and myosin-activation inhibitors on chromosome}

movements

To test for myosin involvement in anaphase chromosome motion, we treated anaphase cells with BDM, ML-7 and Y27632. The drugs were added several minutes after disjunction of the bivalents, after the partner half-bivalents moved sufficiently poleward to determine (post hoc) their rate of movement but early enough so that we could detect (post hoc) effects of the drugs on movement.

BDM inhibits motility by acting directly on myosin (review in Fabian and Forer 2005; Forer and Fabian 2005). BDM added to locust spermatocytes in anaphase generally slowed or stopped chromosome movement (Table I). In general, for this and other inhibitors, different chromosome pairs in the same cell often were affected differently: for example, in Figure 5 which illustrates two different separating half-bivalent pairs in the same cell, BDM caused one pair to slow and the other pair to stop moving.

Myosin also can be inhibited indirectly, by blocking its phosphorylation. Myosin is activated by phosphorylation of its regulatory light chain mainly through myosin light chain kinase (MLCK) or Rho-kinase (Rho-K) (review in Matsumura 2005). MLCK and Rho-K, which have been shown to have different spatial roles in phosphorylating myosin (Totsukawa et al. 2000; 2004; Katoh et al. 2001; Niggli et al. 2006), can be inhibited by ML-7 (Saitoh et al. 1987) and Y27632, respectively (Narumiya et al. 2000; Ishizaki et al. 2000). ML-7 (Fig. 6) or Y27632 (Fig. 7) added to anaphase locust spermatocytes stopped, slowed, or rarely accelerated (ML-7 only) chromosome movements (Table I; Fig 6). [Because of the small numbers of pairs studied, we cannot be certain whether or not the absence of acceleration with Y-27632 represents a real difference from ML-7.] These drugs were about as effective as 
BDM at slowing/stopping chromosome movement (Table I). Therefore, these results support the previous ones obtained with BDM, implicating myosin in anaphase chromosome movements. The inhibition of chromosome movement in locust spindles by both ML-7 and Y27632 suggests that non-muscle myosin activity in mitosis in locust cells might be controlled through both Rho-K and MLCK, unlike in crane-fly spermatocytes where ML-7 did not stop or slow chromosome movements (Fabian and Forer 2005).

For both BDM and Y27632, chromosome movement sometimes recovered while cells still were immersed in the drug (Table I). Since the inhibitors remained in the solution bathing the cells, which periodically was refreshed, it seems unlikely that recovery is due to metabolic degradation of the intracellular inhibitor, but rather to the cell being able to circumvent the blocked myosin.

\section{Effects of actin inhibitors on chromosome movements}

To test for possible roles of actin in chromosome movement we treated anaphase cells with actin inhibitors cytochalasin D (CD) and latrunculin B (LatB). CD is an inhibitor of actin polymerization (Cooper 1987; Sampath and Pollard 1991); its effects on various types of cells and motile processes were reviewed in Forer and Pickett-Heaps (2003). LatB depolymerises actin filaments and binds to actin monomers (Coue et al. 1987; Ayscough 1998; Spector et al. 1983; Yarmola et al. 2000; Morton et al. 2000). When added during anaphase, CD had little effect on chromosome movements in locust spermatocytes (Table I; Fig. 8), while LatB generally slowed, stopped or accelerated chromosome movements (Table I; Fig. 9). There were similar differences between $\mathrm{CD}$ and LatB when added earlier. CD added during metaphase ( 2 cells), 1-14 minutes before anaphase onset, had no effect on chromosome movement in subsequent anaphase. However, LatB added during metaphase, 6-13 min. before 
anaphase (2 cells), disturbed chromosome movement during subsequent anaphase; movements were not with constant speeds through all anaphase, but rather were biphasic. In the initial phase, some of the chromosomes moved slightly slower than normal or in the lower range of normal values, while in the second phase, all the chromosomes moved with slower than normal speeds $(0.25-0.4 \mu \mathrm{m} / \mathrm{min})$, compared to $0.59-2.13 \mu \mathrm{m} / \mathrm{min}$ in control cells. When LatB is added during prometaphase ( 1 cell), 25 minutes before anaphase, the chromosomes disjoined very slowly, and they failed to finish anaphase. These results indicate that actin is required for normal anaphase in locust spermatocytes.

LatB added in metaphase, and in some cases when added in anaphase, also seemed to affect how far apart the two half-bivalents separate, in that the half-bivalents didn't move as far apart as in control cells; the total distance the chromosomes moved in treated cells (15-16 $\mu \mathrm{m})$ was below the shortest distance we recorded in control cells $(17 \mu \mathrm{m})$.

To test whether actin is absent from the treated spindles we stained some of the preparations with phalloidin. In cells treated with LatB for 5-10 minutes, filamentous actin in the spindle is totally or almost completely absent (Fig. 10). Thus LatB treatment caused loss of spindle actin, as in other cells (Fabian and Forer 2005).

All the inhibitors we used had reversible effects on chromosome movement. After they were removed from the preparations, the chromosomes generally resumed their initial speeds, they finished anaphase, and the cells underwent cytokinesis. Sometimes, however, chromosome movement after washing out the drug was slower than while in the drug (Table I), as also described in crane-fly spermatocytes treated with LatB or BDM (Fabian and Forer 2005).

There are several differences between crane-fly spermatocytes and locust 
spermatocytes (Table II). One is the acceleration of chromosome movement: CD, LatB and ML-7 sometimes caused acceleration (by 50-80\%) of chromosome movement during anaphase in locust spermatocytes (Table I), but CD and LatB never caused acceleration in crane-fly spermatocytes. Another difference between crane-fly and locust spermatocytes is that $\mathrm{CD}$ added in anaphase or in metaphase does not block chromosome movement in locust spermatocytes (Tables I) but it does block it in crane-fly spermatocytes (Table II), an effect which may be due to the different organisation of spindle actin in the two cell types.

\section{Effects of inhibitors on cytokinesis}

Cytokinesis in control locust spermatocytes lasts about 15 minutes. We did not study directly the effect of various inhibitors on cytokinesis, but we observed that actin inhibitors (LatB and CD) and Rho-K inhibitor (Y27632) block furrow initiation and cytokinesis when added during metaphase or anaphase, regardless of the drug being removed or not by the time cytokinesis should have started. The MLCK inhibitor (ML-7) did not block cytokinesis initiation and completion when it was removed from the preparations before the start of cytokinesis.

\section{Effects of actin inhibitors on the poleward flux of tubulin}

Previous studies on crane-fly spermatocytes showed that actin and myosin are involved in poleward tubulin flux (Silverman-Gavrila and Forer 2000), so we tested this in locust spermatocytes. We stained locust preparations for acetylated tubulin (stable) versus tyrosinated tubulin (total tubulin). The gap in acetylation of the kinetochore microtubules at the kinetochores (arrowheads in Fig. 11), which on average is $0.3 \mu \mathrm{m}$ long (Fig. 12), indicates that there is flux along kinetochore microtubules in normal (control) metaphase locust spermatocytes (discussion in Wilson et al. 1994). In control late anaphase cells the gap is 
considerably smaller than in metaphase cells, which indicates that tubulin flux continues during anaphase, but by late anaphase it is reduced relative to metaphase (Fig. 11). To test if actin is required for tubulin flux in locust spermatocytes, we treated the cells with LatB, to inhibit actin, and then stained for acetylated vs. tyrosinated tubulin. When actin is inhibited, the gap in acetylation along kinetochore microtubules at metaphase was drastically reduced (Fig. 12), and was completely abolished in many of the cells. In anaphase cells, the gap in acetylation also decreased after treatment with LatB (Fig. 12). These results suggest that tubulin flux along kinetochore microtubules is an actin-dependent process in locust spermatocytes, similar to that in crane-fly spermatocytes. 


\section{DISCUSSION}

We studied actin and myosin involvement in chromosome movements in locust spermatocytes because much of the previous evidence for actin and myosin involvement in anaphase movements was from experiments using spermatocytes from a single species, cranefly spermatocytes, and we wanted to see how general the phenomenon was. Our data implicate actin and myosin in anaphase chromosome movements in locust spermatocytes, similar to crane-fly spermatocytes, but there are some differences in the details of their organization and function.

Actin and myosin are present in locust spermatocytes in positions and with patterns of distribution that are consistent with them having a role in anaphase chromosome movement. Actin has been documented previously in locust spermatocyte spindles by Gawadi (1974) in electron micrographs, using heavy meromyosin binding to actin filaments; by Beier and Hauser (1981) after immunostaining non-treated cells with actin antibodies; and by Daub and Hauser (1986) after immunostaining vanadate treated locust cells with actin antibodies. Using confocal microscopy of phalloidin-stained locust spermatocytes, we found short actin filaments and punctate actin in the spindle, associated with spindle microtubules, and we found longer actin filaments in a strongly stained "cage" of filaments around the spindle. In crane-fly spermatocytes, on the other hand, there is no such cage, and the actin filaments in the spindle are longer and associated primarily with the kinetochore microtubules.

With respect to myosin, we know of no previous reports of myosin being present in locust spermatocyte spindles. Through confocal microscope studies we showed that myosin is present along the spindle fibres (kinetochore and non-kinetochore ones) where it co-localizes with tubulin, similar to its localisation in crane-fly spermatocytes. 
Chromosome movements in locust spermatocytes were affected by actin and myosin inhibitors, but the effects were somewhat different than in crane-fly spermatocytes. All of the inhibitors we used altered chromosome movements during anaphase but they showed a larger spectrum of effects than in crane-fly spermatocytes (Table II). The two major differences between locust spermatocytes and crane-fly spermatocytes are in the effects of ML-7 and CD. In crane-fly spermatocytes ML-7 either has no effect on movement or it causes acceleration (Fabian and Forer 2005), whereas in locust spermatocytes ML-7 generally causes stopping/slowing and rarely acceleration or no effect (Table I). This might be because in crane-fly spermatocytes spindle myosin is activated primarily by Rho-kinase, whereas in locust spermatocytes myosin is phosphorylated almost equally by the two kinases (Rho-kinase and MLCK). This interpretation is consistent with results obtained in other cellular systems in which Rho-kinase is more active at the cell centre, while MLCK is more active at the cell periphery (Totsukawa et al. 2004; Matsumura 2005). Also, it is consistent with the more rapid recovery (while in the presence of the drug) of majority of the half-bivalents in locust spermatocytes treated with Y27632 compared to crane-fly spermatocytes. This suggests that backup mechanisms are available for the cell to overcome interference with anaphase and these mechanisms are more easily/readily turned on.

In locust spermatocytes the only effect of $\mathrm{CD}$ added in anaphase or metaphase was to accelerate some of the chromosomes (Table I), whereas in crane-fly spermatocytes CD added in anaphase or metaphase generally slowed or stopped chromosome movement (Forer and Pickett-Heaps 1998; Fabian and Forer 2005). Thus, actin in locust spermatocytes would seem to function differently than in crane-fly spermatocytes. These differences in effects of CD in the two cell types might be due to the different organization of actin in locust spindles 
compared to crane-fly spindles, with short stretches of actin in locust spindle versus long actin filaments in crane-fly spindles. Also, the presence of an "actin cage" around the spindle in locust spermatocytes, similar to plant spindles (Staiger and Schliwa 1987), might interfere with $\mathrm{CD}$ action. The similar effects of LatB in slowing/stopping chromosome movements in both locust and crane-fly spermatocytes (Table II) confirmed that actin is involved in anaphase chromosome movements in these two cell types. The stopping/slowing effects of LatB added in anaphase are less severe in locust spermatocytes than those in crane-fly spermatocytes, while those of LatB added in metaphase are more severe (Table II), which may indicate that some spindle components are organized in a different temporal manner, or that there are additional alternate ways to move chromosomes to the pole in locust spermatocytes.

In some aspects there are similarities between the two cell types. For one, actin and myosin seem to be involved in producing flux along kinetochore microtubules. In locusts, LatB blocks, or drastically reduces, poleward flux of tubulin in both metaphase and anaphase cells. Metaphase flux in crane-fly spermatocytes similarly is inhibited by anti-actin drugs, and also by anti-myosin drugs (Silverman-Gavrila and Forer 2000). Thus in both cell types flux of tubulin along kinetochore microtubules is driven, at least in part, by actin and myosin. Our experiments on locust spermatocytes indicate that flux, as measured by gap in acetylation, continues to late anaphase, results which are consistent with measurements of flux in grasshopper spermatocytes (Chen and Zhang 2004) and crane-fly spermatocytes (LaFountain et al. 2004).

There are other similarities between locust and crane-fly spermatocytes. For example, different chromosome pairs in a cell do not respond the same to a specific treatment (Forer and Pickett-Heaps 1998; Wong and Forer 2003; Fabian and Forer 2005). In locust 
spermatocytes some of the slowed or stopped half-bivalents recovered while still in the presence of the inhibitor, mainly in the cells treated with LatB and Y27632 (Table I), as some of the chromosomes did in crane-fly spermatocytes (Forer and Pickett-Heaps 1998; Fabian and Forer 2005). Another similarity is that, sometimes, the chromosome movements in both species became slower after removing the drug (Table I; Fabian and Forer 2005). These results are consistent with the notion that there are alternative ways in which the kinetochore fibres function, even in the same spindle (Fabian and Forer 2005; Cameron et al. 2006), and that when one mechanism of movement is inhibited or interfered with, another mechanism subsequently is activated to move the chromosomes poleward.

In summary, actin, myosin and other cytoskeletal proteins are present in locust spermatocytes and the effects of inhibitors indicate a role for actin and myosin in anaphase chromosome movements and in flux in locust spindles. 


\section{ACKNOWLEDGEMENTS}

The authors are grateful to Dr. B. Loughton (York University) for providing locusts and for helpful suggestions, to Dr. K. Johansen (Iowa State University, IA) for the skeletor, megator and chromator antibodies and to Dr. D. Andrew (Johns Hopkins University, MD) for the titin antibodies. This work was supported by Natural Sciences and Engineering Research Council of Canada to AF. 


\section{REFERENCES}

Ault GA (1984) Unipolar orientation stability of the sex univalent in the grasshoper (Melanoplus sanguinipes). Chromosoma 89: 201-205

Ault JG (1986) Stable versus unstable orientations of sex chromosomes in two grasshopper species. Chromosoma 93: 298-304

Ault JG, Nicklas RB (1989) Tension, microtubule rearrangements, and the proper distribution of chromosomes in mitosis. Chromosoma 98: 33-39

Ayscough K (1998) Use of latrunculin-A, an actin monomer-binding drug. Methods Enzymol 298: $18-25$

Beier AM, Hauser M (1981) Die Chromosomenbewegung in der Anaphase. Verh Dtsch Zool Ges 1981: 85-96

Belar K (1929) Beitrage zur Kausalanalyse der Mitose. II. Untersuchungen an den Spermatocyten von Chorthippus (Stenobothrus) lineatus Pans. Z wiss Biol Arch Entwicklungsmechanik 118: 359-484

Cameron LA, Yang G, Cimini D, Canman JC, Kisurina-Evgenieva O, Khodjakov A, Danuser G, Salmon ED (2006) Kinesin 5-independent poleward flux of kinetochore microtubules in PtK1 cells. J Cell Biol 173: 173-179

Chen W, Zhang D (2004) Kinetochore fibre dynamics outside the context of the spindle during anaphase. Nat Cell Biol 6: 227-231

Cooper JA (1987) Effects of cytochalasin and phalloidin on actin. J Cell Biol 105: 1473-1478

Coue M, Brenner SL, Spector I, Korn ED (1987) Inhibition of actin polymerization by latrunculin A. FEBS Lett 213: 316-318

Daub AM, Hauser M (1986) In vivo effects of ortho-vanadate on spindle structure and 
dynamics of locust spermatocytes I. Chromosoma 93: 271-280

Daub AM, Hauser M (1988) Taxol affects meiotic spindle function in locust spermatocytes. Protoplasma 142: 147-155

Fabian L, Forer A (2005) Redundant mechanisms for anaphase chromosome movements: crane-fly spermatocyte spindles normally use actin filaments but also can function without them. Protoplasma 225: 169-184

Fabian L, Xia X, Venkitaramani DV, Johansen KM, Johansen J, Andrew DJ, Forer A (2006) Titin in insect spermatocyte spindle fibres associates with microtubules, actin, myosin and the matrix proteins skeletor, megator and chromator. In preparation.

Forer A (1969) Chromosome movements during cell division. In: Lima-de-Faria A (ed) Handbook of Molecular Cytology. North-Holland Publishing Company, Amsterdam, pp 553-601

Forer A (1974) Possible roles of microtubules and actin-like filaments during cell-division. In: Padilla GM, Cameron IL,Zimmerman A (eds) Cell Cycle Controls. Academic Press, New York and London, pp 319-336

Forer A, Fabian L (2005) Does 2,3-butanedione monoxime inhibit nonmuscle myosin? Protoplasma 225: 1-4

Forer A, Pickett-Heaps JD (1998) Cytochalasin D and latrunculin affect chromosome behaviour during meiosis in crane-fly spermatocytes. Chromosome Res 6: 533-549

Forer A, Pickett-Heaps J (2005) Fibrin clots keep non-adhering living cells in place on glass for perfusion or fixation. Cell Biol Int 29: 721-730

Forer A, Wilson PJ (2000) Evidence that kinetochore fibre microtubules shorten predominantly at the pole in anaphase flea-beetle spermatocytes. Chromosome Res 8: 
$151-163$

Forer A, Spurck T, Pickett-Heaps JD, Wilson PJ (2003) Structure of kinetochore fibres in crane-fly spermatocytes after irradiation with an ultraviolet microbeam: neither microtubules nor actin filaments remain in the irradiated region. Cell Motil Cytoskeleton 56: 173-192

Gawadi N (1971) Actin in the mitotic spindle. Nature 234: 410

Gawadi N (1974) Characterization and distribution of microfilaments in dividing locust testis cells. Cytobios 10: 17-35

Ilagan AB, Forer A (1997) Effects of ultraviolet-microbeam irradiation of kinetochores in crane-fly spermatocytes. Cell Motil Cytoskeleton 36: 266-275

Ishizaki T, Uehata M, Tamechika I, Keel J, Nonomura K, Maekawa M, Narumiya S (2000) Pharmacological properties of Y-27632, a specific inhibitor of rho-associated kinases. Mol Pharmacol 57: 976-983

John B, Hewitt GM (1966) Karyotype stability and DNA variability in the Acrididae. Chromosoma 20: 155-172

Katoh K, Kano Y, Amano M, Kaibuchi K, Fujiwara K (2001) Stress fiber organization regulated by MLCK and Rho-kinase in cultured human fibroblasts. Am J Physiol Cell Physiol 280: C1669-79

Kilmartin JV, Wright B, Milstein C (1982) Rat monoclonal antitubulin antibodies derived by using a new nonsecreting rat cell line. J Cell Biol 93: 576-582

LaFountain JR,Jr, Cohan CS, Siegel AJ, LaFountain DJ (2004) Direct visualization of microtubule flux during metaphase and anaphase in crane-fly spermatocytes. Mol Biol Cell 15: 5724-5732 
LaFountain JRJ, Janicke MA, Balczon R, Rickards GK (1992) Cytochalasin induces abnormal anaphase in crane-fly spermatocytes and causes altered distribution of actin and centromeric antigens. Chromosoma 101: 425-441

Machado C, Sunkel CE, Andrew DJ (1998) Human antibodies reveal titin as a chromosomal protein. J Cell Biol 141: 321-333

Maddox P, Straight A, Coughlin P, Mitchison TJ, Salmon ED (2003) Direct observation of microtubule dynamics at kinetochores in Xenopus extract spindles: implications for spindle mechanics. J Cell Biol 162: 377-382

Margolin W (2005) Bacterial mitosis: actin in a new role at the origin. Curr Biol 15: R259-61

Matsumura F (2005) Regulation of myosin II during cytokinesis in higher eukaryotes. Trends Cell Biol 15: 371-377

McClung CE (1902) The spermatocyte divisions of the Locustidae. Kans Univ Sc Bull 1: 185231

McIntosh JR, Grishchuk EL, West RR (2002) Chromosome-microtubule interactions during mitosis. Annu Rev Cell Dev Biol 18: 193--219

Mitchison TJ (1989) Polewards microtubule flux in the mitotic spindle: evidence from photoactivation of fluorescence. J Cell Biol 109: 637-652

Moens PB (1969) The fine structure of meiotic chromosome polarization and pairing in Locusta migratoria spermatocytes. Chromosoma 28: 1-25

Mohr OL (1914) Studien uber die Chromatinreifung der mannlichen Geschlechtszellen bei Locusta viridissima. Arch Biologie 29: 579-752

Morton WM, Ayscough KR, McLaughlin PJ (2000) Latrunculin alters the actin-monomer subunit interface to prevent polymerization. Nat Cell Biol 2: 376-378 
Narumiya S, Ishizaki T, Uehata M (2000) Use and properties of ROCK-specific inhibitor Y27632. Methods Enzymol 325: 273-284

Nicklas RB, Waters JC, Salmon ED, Ward SC (2001) Checkpoint signals in grasshopper meiosis are sensitive to microtubule attachment, but tension is still essential. J Cell Sci 114: $4173-4183$

Niggli V, Schmid M, Nievergelt A (2006) Differential roles of Rho-kinase and myosin light chain kinase in regulating shape, adhesion, and migration of HT1080 fibrosarcoma cells. Biochem Biophys Res Commun 343: 602-608

Palazzo A, Ackerman B, Gundersen GG (2003) Cell biology: Tubulin acetylation and cell motility. Nature 421: 230

Paliulis LV, Nicklas RB (2000) The reduction of chromosome number in meiosis is determined by properties built into the chromosomes. J Cell Biol 150: 1223-1232

Qi H, Rath U, Wang D, Xu YZ, Ding Y, Zhang W, Blacketer MJ, Paddy MR, Girton J, Johansen J, Johansen KM (2004) Megator, an essential coiled-coil protein that localizes to the putative spindle matrix during mitosis in Drosophila. Mol Biol Cell 15: $4854-4865$

Rath U, Wang D, Ding Y, Xu YZ, Qi H, Blacketer MJ, Girton J, Johansen J, Johansen KM (2004) Chromator, a novel and essential chromodomain protein interacts directly with the putative spindle matrix protein skeletor. J Cell Biochem 93: 1033-1047

Rebollo E, Arana P (1995) A comparative study of orientation at behavior of univalent in living grasshopper spermatocytes. Chromosoma 104: 56-67

Rees H, Jamieson A (1954) A supernumerary chromosome in Locusta. Nature 173: 43-44

Ris $H$ (1949) The anaphase movement of chromosomes in the spermatocytes of the 
grasshopper. Biol Bull 90-106

Rogers GC, Rogers SL, Sharp DJ (2005) Spindle microtubules in flux. J Cell Sci 118: 11051116

Saitoh M, Ishikawa T, Matsushima S, Naka M, Hidaka H (1987) Selective inhibition of catalytic activity of smooth muscle myosin light chain kinase. J Biol Chem 262: 77967801

Sampath P, Pollard TD (1991) Effects of cytochalasin, phalloidin, and $\mathrm{pH}$ on the elongation of actin filaments. Biochemistry 30: 1973-1980

Sampson K, Pickett-Heaps JD, Forer A (1996) Cytochalasin D blocks chromosomal attachment to the spindle in the green alga Oedogonium. Protoplasma 192: 130-144

Sanger JM, Mittal B, Dome JS, Sanger JW (1989) Analysis of cell division using fluorescently labelled actin and myosin in living PtK2 cells. Cell Motil Cytoskeleton 14: $201-219$

Sawin KE, Mitchison TJ (1991) Poleward microtubule flux mitotic spindles assembled in vitro. J Cell Biol 112: 941-954

Schmit AC, Lambert AM (1988) Plant actin filament and microtubule interactions during anaphase-telophase transtitions: effect of antagonist drugs. Biol Cell 64: 309-319

Schmit AC, Lambert AM (1990) Microinjected fluorescent phalloidin in vivo reveals the Factin dynamics and assembly in higher plant mitotic cells. Plant Cell 2: 129-138

Sillers PJ, Forer A (1981) Autosomal spindle fibres influence subsequent sex-chromosome movements in crane-fly spermatocytes. J Cell Sci 49: 51-67

Silverman-Gavrila RV, Forer A (2000) Chromosome attachment to the spindle in crane-fly spermatocytes requires actin and is necessary to initiate the anaphase-onset checkpoint. 


\section{Protoplasma 212: 56-71}

Silverman-Gavrila RV, Forer A (2000) Evidence that actin and myosin are involved in the poleward flux of tubulin in metaphase kinetochore microtubules of crane-fly spermatocytes. J Cell Sci 113 ( Pt 4): 597-609

Silverman-Gavrila RV, Forer A (2001) Effects of anti-myosin drugs on anaphase chromosome movement and cytokinesis in crane-fly primary spermatocytes. Cell Motil Cytoskeleton 50: 180-197

Silverman-Gavrila RV, Forer A (2003) Myosin localisation during meiosis I of crane-fly spermatocytes gives indications about its role in division. Cell Motil Cytoskeleton 55: 97-113

Spector I, Shochet NR, Kashman Y, Groweiss A (1983) Latrunculins: novel marine toxins that disrupt microfilament organization in cultured cells. Science 219: 493-495

Staiger CJ, Schliwa M (1987) Actin localisation and function in higher plants. Protoplasma 141: $1-12$

Totsukawa G, Wu Y, Sasaki Y, Hartshorne DJ, Yamakita Y, Yamashiro S, Matsumura F (2004) Distinct roles of MLCK and ROCK in the regulation of membrane protrusions and focal adhesion dynamics during cell migration of fibroblasts. J Cell Biol 164: 427439

Totsukawa G, Yamakita Y, Yamashiro S, Hartshorne DJ, Sasaki Y, Matsumura F (2000) Distinct roles of ROCK (Rho-kinase) and MLCK in spatial regulation of MLC phosphorylation for assembly of stress fibers and focal adhesions in 3T3 fibroblasts. J Cell Biol 150: 797-806

Walker DL, Wang D, Jin Y, Rath U, Wang Y, Johansen J, Johansen KM (2000) Skeletor, a 
novel chromosomal protein that redistributes during mitosis provides evidence for the formation of a spindle matrix. J Cell Biol 151: 1401-1412

White MJD (1935) The effects of X-rays on mitosis in the spermatogonial divisions of Locusta migratoria L. Proc R Soc London, Biological Sciences 119: 61-84

Wilson PJ, Forer A (1989) Acetylated alpha-tubulin in spermatogenic cells of the crane fly Nephrotoma suturalis: kinetochore microtubules are selectively acetylated. Cell Motil Cytoskeleton 14: 237-250

Wilson PJ, Forer A (1997) Effects of nanomolar taxol on crane-fly spermatocyte spindles indicate that acetylation of kinetochore microtubules can be used as a marker of poleward tubulin flux. Cell Motil Cytoskeleton 37: 20-32

Wilson PJ, Forer A, Leggiadro C (1994) Evidence that kinetochore microtubules in crane-fly spermatocytes disassemble during anaphase primarily at the poleward end. J Cell Sci 107 ( Pt 11): 3015-3027

Wong R, Forer A (2003) 'Signalling' between chromosomes in crane-fly spermatocytes studied using ultraviolet microbeam irradiation. Chromosome Res 11: 771-786

Wrench WA, Snyder JA (2001) The effect of cytochalasin J on kinetochore structure in PtK $_{1}$ cells is mitotic cycle dependent. Cell Biol Int 25: 815-820

Yarmola EG, Somasundaram T, Boring TA, Spector I, Bubb MR (2000) Actin-latrunculin A structure and function. Differential modulation of actin-binding protein function by latrunculin A. J Biol Chem 275: 28120-28127 


\section{FIGURE LEGENDS}

Figure 1. Normal division in a locust spermatocyte. Phase-contrast images of (A)

prometaphase; (B) metaphase; (C) anaphase; and (D) cytokinesis. The univalent sex

chromosome (arrow in A) does not align at the equator, but stays at one pole during division.

The spindle area is outlined by mitochondria (arrowheads in A, B and D). Scale bar $=10 \mu \mathrm{m}$.

Figure 2. Chromosome movement in a control cell, illustrating one pair of half-bivalents moving with constant separation velocity during anaphase. The dashed line represents the best fit (linear regression) through the indicated points.

Figure 3. Actin and myosin distribution in control locust spermatocytes. (A-F) Confocal microscope images of locust spermatocytes stained with Alexa phalloidin for filamentous actin $(\mathrm{A}, \mathrm{B}, \mathrm{E})$ and tubulin $(\mathrm{C})$ and the merged images of the two channels $(\mathrm{D}, \mathrm{F})$. (A) illustrates a cell in prometaphase, (B-D) illustrate a cell in metaphase and (E-F) illustrate a cell in anaphase. Actin forms a cage of filaments (arrowheads in A, B) around the spindle and the cage is attached to the cortex through several connections of actin filaments (arrows in A, B). Spindle actin is present as stretches of short filaments (open arrowheads in A, B) and as a diffuse, finely punctate mass of actin. (G-I) Confocal microscope images of cells in metaphase $(\mathrm{G}, \mathrm{H})$ and anaphase (I, J) stained for myosin (G, I) and the merged image of the two channels $(\mathrm{H})$. Yellow/orange in (D, F, H) represents co-localisation of the two proteins. (J) Differential interference contrast (DIC) of the cell shown in (I). Scale bars $=5 \mu \mathrm{m}$.

Figure 4. Titin and matrix proteins distribution in control locust spermatocytes. Confocal microscope images of cells in metaphase stained with antibodies against KZ-titin (A); skeletor (D); megator (G); chromator (J); and tubulin (B, E, H, K). Merged images of the two channels 
$(\mathrm{C}, \mathrm{F}, \mathrm{I}, \mathrm{L})$. Yellow/orange in $(\mathrm{C}, \mathrm{F}, \mathrm{I}, \mathrm{L})$ represents co-localisation of the proteins. Scale bars $=5 \mu \mathrm{m}$.

Figure 5. Effects of BDM on chromosome movement in a locust spermatocyte when added during anaphase. Two pairs of half-bivalents from the same cell are shown $(+, \Delta)$. BDM was added after 10 minutes anaphase started (down-pointing arrow) and was washed out after 7 minutes (up-pointing arrow). One pair of half-bivalents stopped $(\Delta)$ and the other drastically slowed $(+)$. The stopped pair resumed movement at normal speed after wash out.

Figure 6. Effect of ML-7 on chromosome movement in a locust spermatocyte when added during anaphase. Two pairs of half-bivalents from the same cell are shown. One pair slowed ( $\square$ ) and one pair accelerated $(\Delta)$ after addition of ML-7 (down-pointing arrow). Sometimes, movement became worse after ML-7 was washed out (up-pointing arrow). The lines represent the best fit (linear regression) through the indicated points. The dashed line is before addition of ML-7.

Figure 7. Effect of Y-27632 on chromosome movement in a locust spermatocyte when added during anaphase. One pair of half-bivalents is shown $(+)$, which slowed about 5 minutes after addition of Y-27632 (down-pointing arrow) and then partially recovered while still in the drug. The effect of Y-27632 is visible only after some minutes, because of the slow permeability of Y-27632 (Narumiya 2000). The lines represent the best fit (linear regression) through the indicated points. The dashed line is before addition of Y-27632 and the solid line is after addition of Y-27632.

Figure 8. Effect of cytochalasinD (CD) on chromosome movement in a locust spermatocyte when added during anaphase. One pair of half-bivalents is shown $(+)$; Chromosomes accelerated after addition of CD (down-pointing arrow) and then slowed while in the presence 
of the drug. The lines represent the best fit (linear regression) through the indicated points. The dashed line is before addition of $\mathrm{CD}$ and the solid line is after addition of $\mathrm{CD}$.

Figure 9. Effects of latrunculinB (LatB) on chromosome movement in locust spermatocytes when added during anaphase. Two pairs of half-bivalents from different cells are shown (+, o). LatB was added at 5 or 6 minutes, respectively, after anaphase started (the two leftmost arrows) and was washed out after 6 , or 4 minutes respectively (the two rightmost arrows). One pair of half-bivalents stopped for few minutes and then started again, at very slow speed $(+)$, while the other pair accelerated after addition of LatB (o). The dashed lines (through the dots) are before addition of LatB and the solid lines (through the dots) are after addition of LatB.

Figure 10. Actin filaments have been completely depolymerized after treatment of locust spermatocytes with latrunculinB for 5 minutes. Confocal microscope image of a cell in anaphase stained with Alexa phalloidin for filamentous actin (A) and DIC image of the same cell illustrating the chromosomes and the spindle fibres (B). Phalloidin stained the chromosomes in this cell; this also occurs sometimes in control cells, as it does in other species such as crane-fly spermatocytes (e.g. Silverman-Gavrila and Forer, 2000; Forer et al., 2003). Scale bars $=5 \mu \mathrm{m}$.

Figure 11. Confocal microscope images of locust spermatocytes in metaphase (A-C;G-I) and anaphase (D-F;J-L) stained for acetylated tubulin (green) and tyrosinated tubulin (red). Yellow/orange in merged images $(\mathrm{C} ; \mathrm{F} ; \mathrm{I} ; \mathrm{L})$ represents co-localisation of the two proteins. Tubulin is acetylated along the kinetochore spindle fibres, except for a short (red) region near the kinetochores, which forms a "gap in acetylation" (arrowheads). The gap in anaphase (D-F) is much smaller than in metaphase (A-C). Treatment with LatB reduces the gap, both in metaphase (G-I) and in anaphase (J-L). Scale bars $=5 \mu \mathrm{m}$. 
Figure 12. Length of the "gap in acetylation" at the kinetochores in control and latrunculinBtreated locust spermatocytes (A). Presence of a gap in metaphase and anaphase indicates that there is poleward flux along kinetochore microtubules in control locust spermatocytes (B; C). The drastically reduced gap in latrunculinB-treated locust spermatocytes $(\mathrm{B} ; \mathrm{C})$ indicates that actin has a role in poleward flux of tubulin in locust cells. 
Table I. Effect of inhibitors added in anaphase on movement of chromosomes

\begin{tabular}{|c|c|c|c|c|c|c|c|c|c|c|c|}
\hline & \multicolumn{7}{|c|}{$\begin{array}{l}\text { Number of half-bivalent pairs } \\
\text { followed }\end{array}$} & \multirow[b]{2}{*}{$\begin{array}{c}\text { Average } \\
\text { separation speeds } \\
\text { (ranges of speeds) } \\
\text { when movements } \\
\text { were slowed, in } \\
\mu \mathrm{m} / \mathrm{min}\end{array}$} & \multirow[b]{2}{*}{$\begin{array}{c}\text { Average } \\
\text { slowing } \\
\text { (x times slower } \\
\text { than before the } \\
\text { drug) }\end{array}$} & \multirow[b]{2}{*}{$\begin{array}{c}\text { Average } \\
\text { separation speeds } \\
\text { (ranges of speeds) } \\
\text { when movements } \\
\text { were accelerated, } \\
\text { in } \mu \mathrm{m} / \mathrm{min}\end{array}$} & \multirow[b]{2}{*}{$\begin{array}{l}\text { Average } \\
\text { acceleration } \\
\text { (x times } \\
\text { faster than } \\
\text { before the } \\
\text { drug) }\end{array}$} \\
\hline & $\stackrel{\pi}{0}$ & 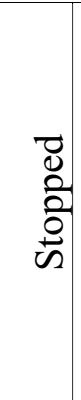 & 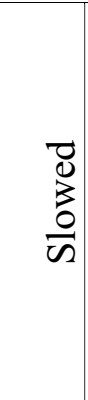 & 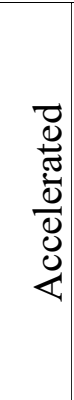 & 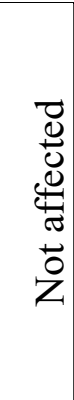 & 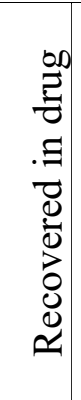 & 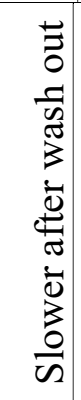 & & & & \\
\hline $\begin{array}{l}\text { Control } \\
\text { (16 cells) }\end{array}$ & 32 & - & - & - & - & - & - & - & - & $\begin{array}{c}1.17 \\
(0.59-2.31)\end{array}$ & - \\
\hline $\begin{array}{c}\text { BDM } \\
(7 \text { cells })\end{array}$ & 21 & 4 & 12 & 0 & 5 & 2 & 2 & $\begin{array}{c}0.75 \\
(0.33-1.18)\end{array}$ & 2.37 & - & - \\
\hline $\begin{array}{l}\text { Y27632* } \\
\text { (2 cells) }\end{array}$ & 8 & 2 & 5 & 0 & 1 & 6 & 0 & $\begin{array}{c}0.65 \\
(0.33-1.06)\end{array}$ & 2.1 & - & - \\
\hline $\begin{array}{c}\text { ML-7 } \\
(2 \text { cells })\end{array}$ & 7 & 1 & 4 & 1 & 1 & 0 & 2 & $\begin{array}{c}0.98 \\
(0.8-1.14)\end{array}$ & 1.42 & 1.36 & 1.79 \\
\hline $\begin{array}{c}\text { LatB } \\
\text { (7 cells) }\end{array}$ & 25 & 4 & 9 & 5 & 7 & 6 & 8 & $\begin{array}{c}0.85 \\
(0.37-1.84)\end{array}$ & 2.25 & $\begin{array}{c}1.86 \\
(1.18-2.62)\end{array}$ & 1.5 \\
\hline $\begin{array}{c}\mathrm{CD} \\
(2 \text { cells })\end{array}$ & 7 & 0 & 0 & 2 & 5 & - & - & - & - & $\begin{array}{c}1.6 \\
(1.35-1.85)\end{array}$ & 1.61 \\
\hline
\end{tabular}


Table II. Effects of actin and myosin inhibitors on chromosome movement in crane-fly and locust spermatocytes

\begin{tabular}{|c|c|c|}
\hline \multirow{2}{*}{ Inhibitor } & \multicolumn{2}{|c|}{ Effects on anaphase chromosome movements in } \\
\hline & crane-fly spermatocytes & locust spermatocytes \\
\hline LatB added in anaphase & $\begin{array}{l}\text { stop; slow; no effect } \\
\text { (Forer and Pickett-Heaps, 1998; } \\
\text { Fabian and Forer, 2005) }\end{array}$ & $\begin{array}{c}\text { slow; stop; accelerate; no } \\
\text { effect }\end{array}$ \\
\hline LatB added in metaphase & $\begin{array}{l}\text { slow; stop; variable speeds (Forer } \\
\text { and Pickett-Heaps, 1998) }\end{array}$ & variable speeds \\
\hline $\begin{array}{l}\text { LatB added in late } \\
\text { prometaphase }\end{array}$ & $\begin{array}{l}\text { slow; stop; variable speeds } \\
\text { (Forer and Pickett-Heaps, 1998; } \\
\text { Fabian and Forer, 2005) }\end{array}$ & $\begin{array}{l}\text { disjoin slowly; } \\
\text { slow, and anaphase not } \\
\text { completed }\end{array}$ \\
\hline CD added in anaphase & $\begin{array}{l}\text { stop; slow; no effect } \\
\text { (Forer and Pickett-Heaps, 1998) }\end{array}$ & no effect; accelerate \\
\hline CD added in metaphase & $\begin{array}{c}\text { disjoin and stop; slow; variable } \\
\text { speeds (Forer and Pickett-Heaps, } \\
1998)\end{array}$ & no effect \\
\hline BDM added in anaphase & $\begin{array}{c}\text { stop; slow; no effect } \\
\text { (Silverman-Gavrila and Forer, } \\
\text { 2001; Fabian and Forer, 2005) }\end{array}$ & slow; stop; no effect \\
\hline ML-7 added in anaphase & $\begin{array}{c}\text { no effect; accelerate } \\
\text { (Fabian and Forer, 2005) }\end{array}$ & slow; stop; accelerate \\
\hline Y-27632 added in anaphase & $\begin{array}{c}\text { stop; slow } \\
\text { (Fabian and Forer, 2005) }\end{array}$ & stop; slow \\
\hline
\end{tabular}


Fig. 1. Locust spermatocyte in division
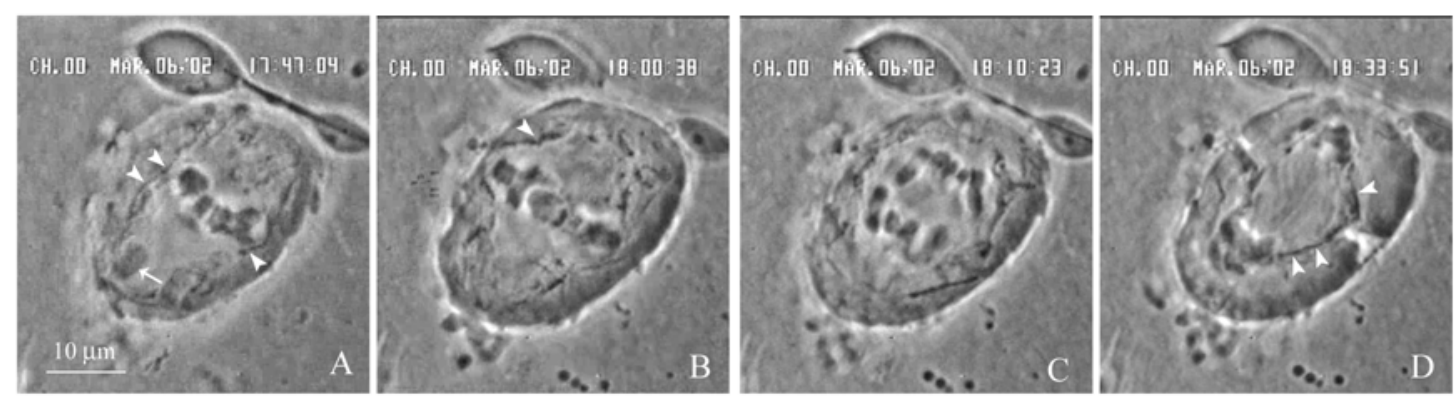

Fig. 2. Control

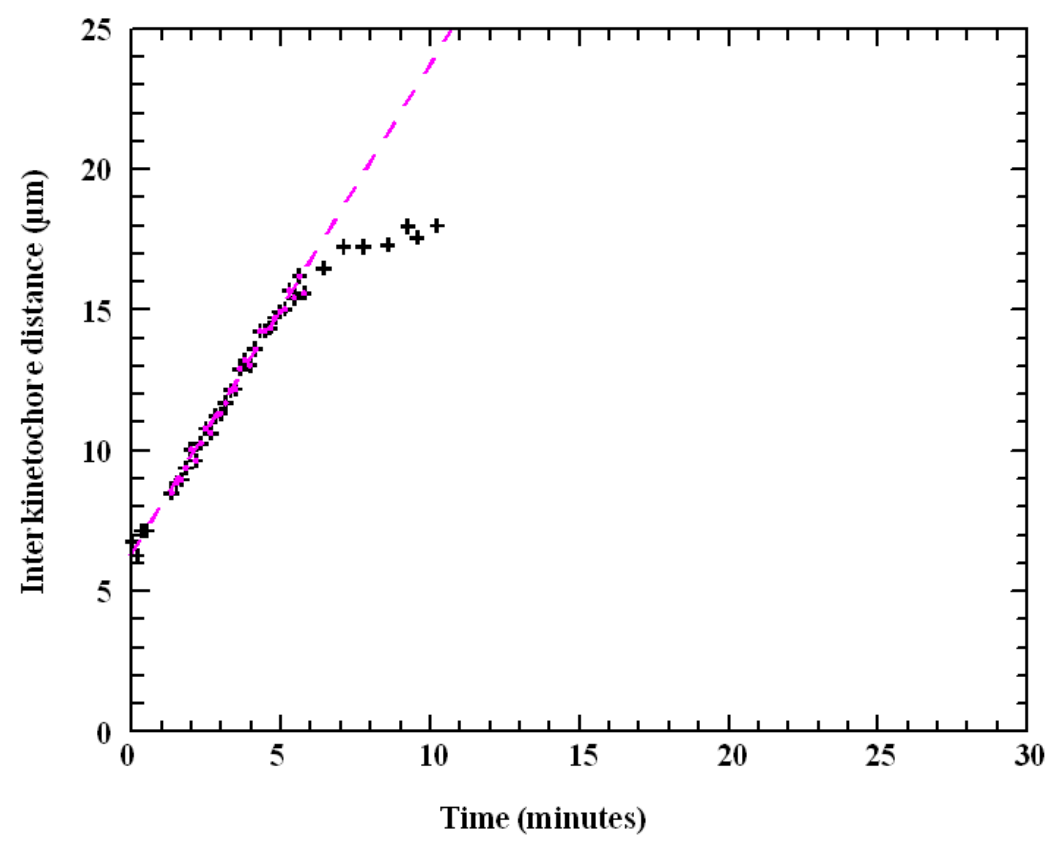


Fig. 3. Actin and Myosin distribution in locusts

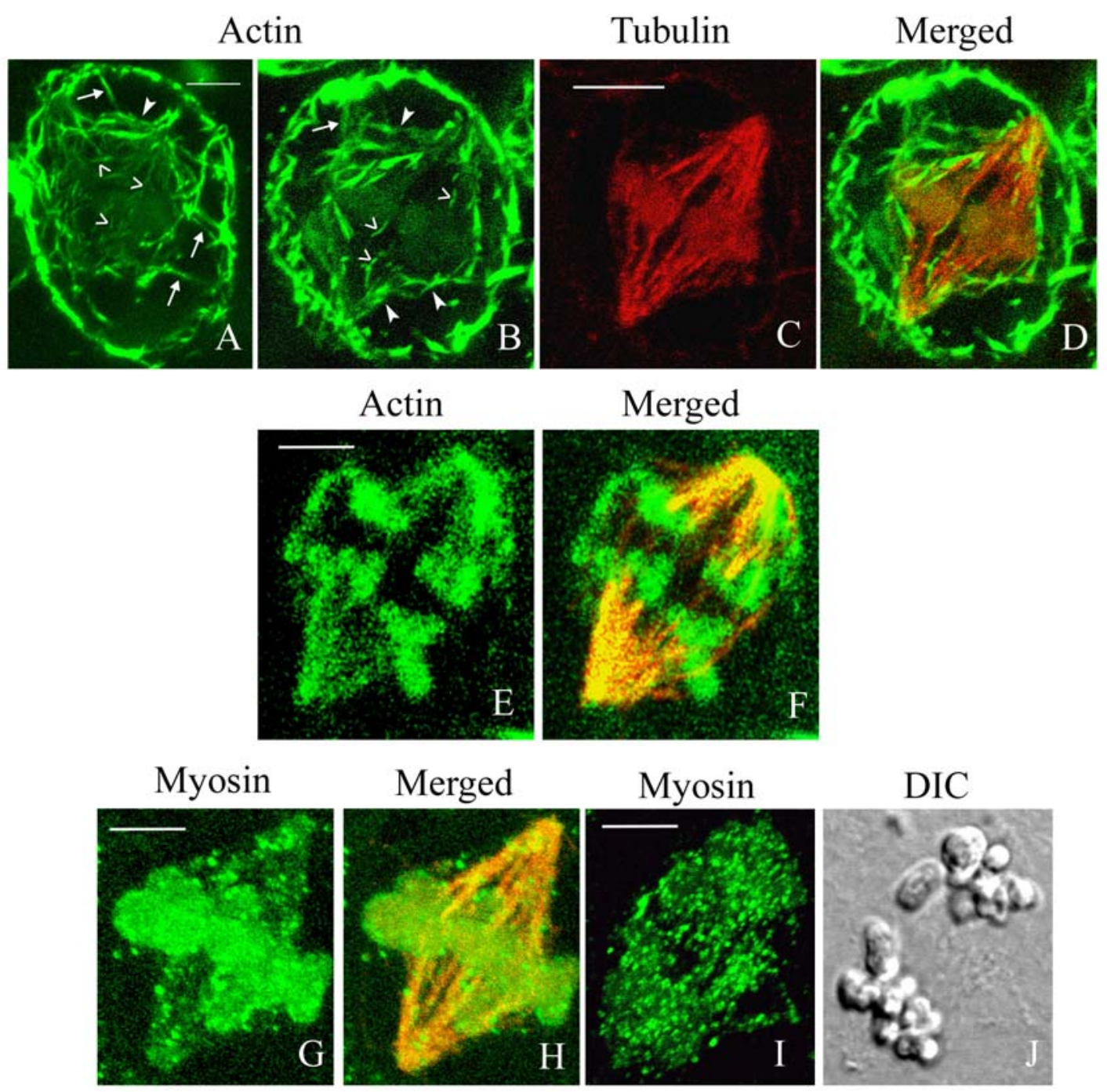


Fig. 4. Matrix and muscle protein distribution

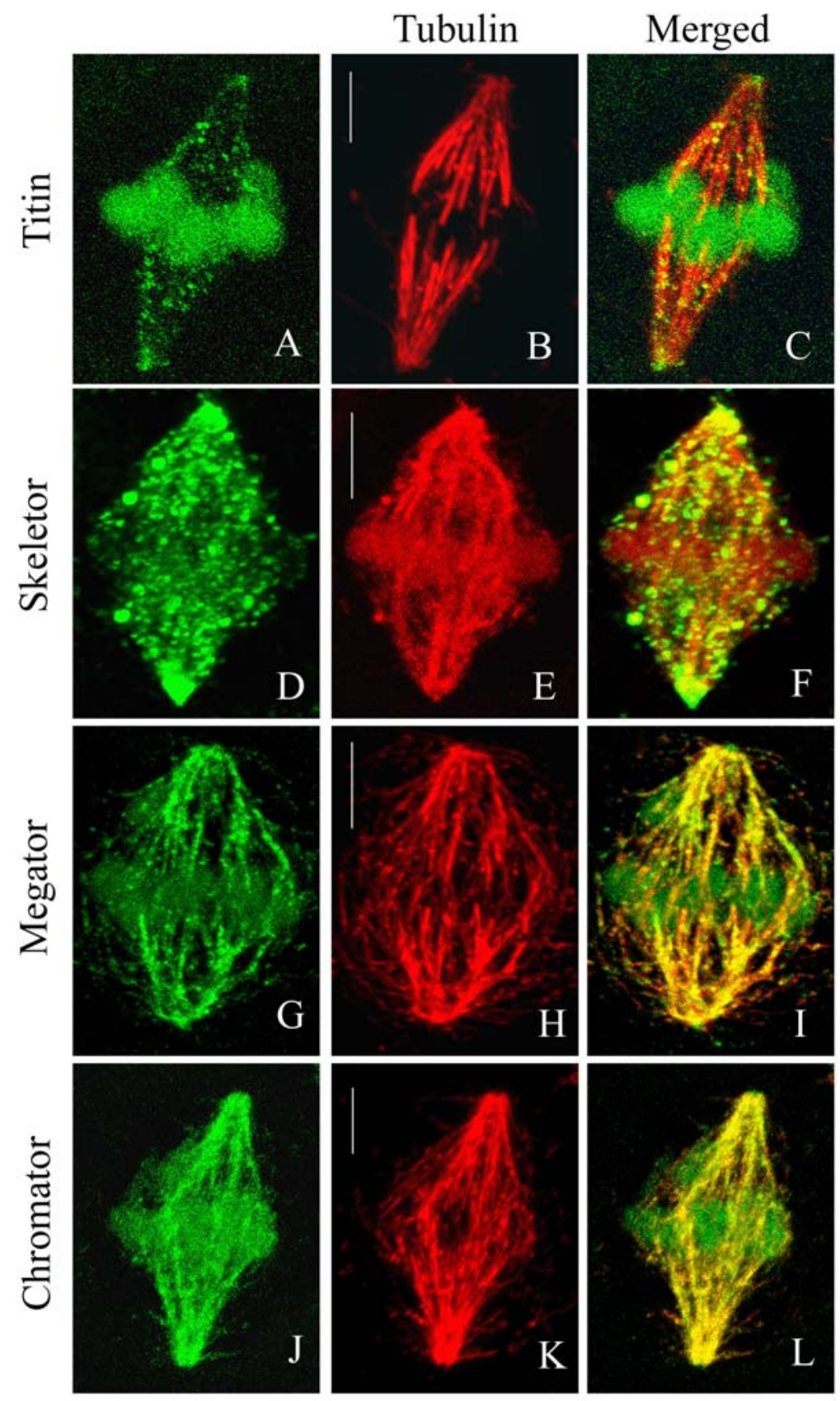



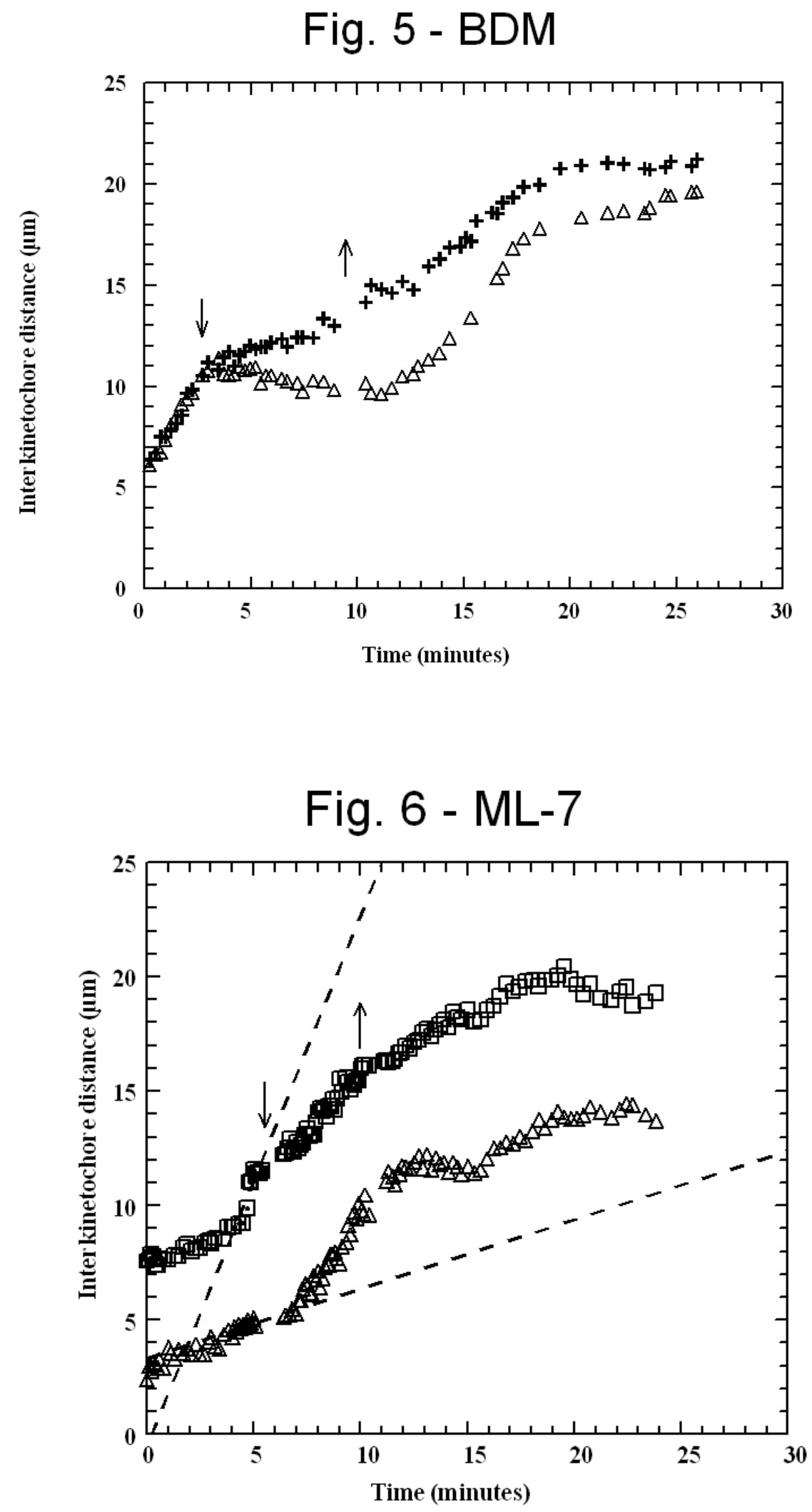
Fig. 7 - Y27632

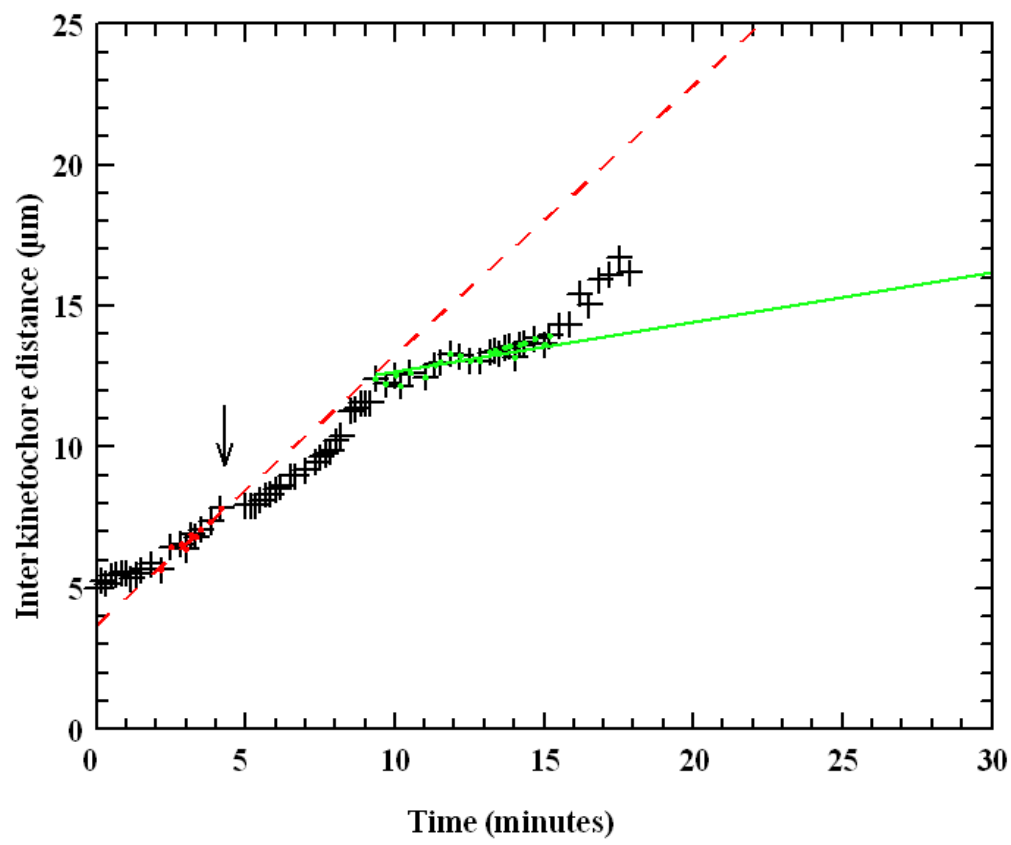

Fig. 8 - CytochalasinD

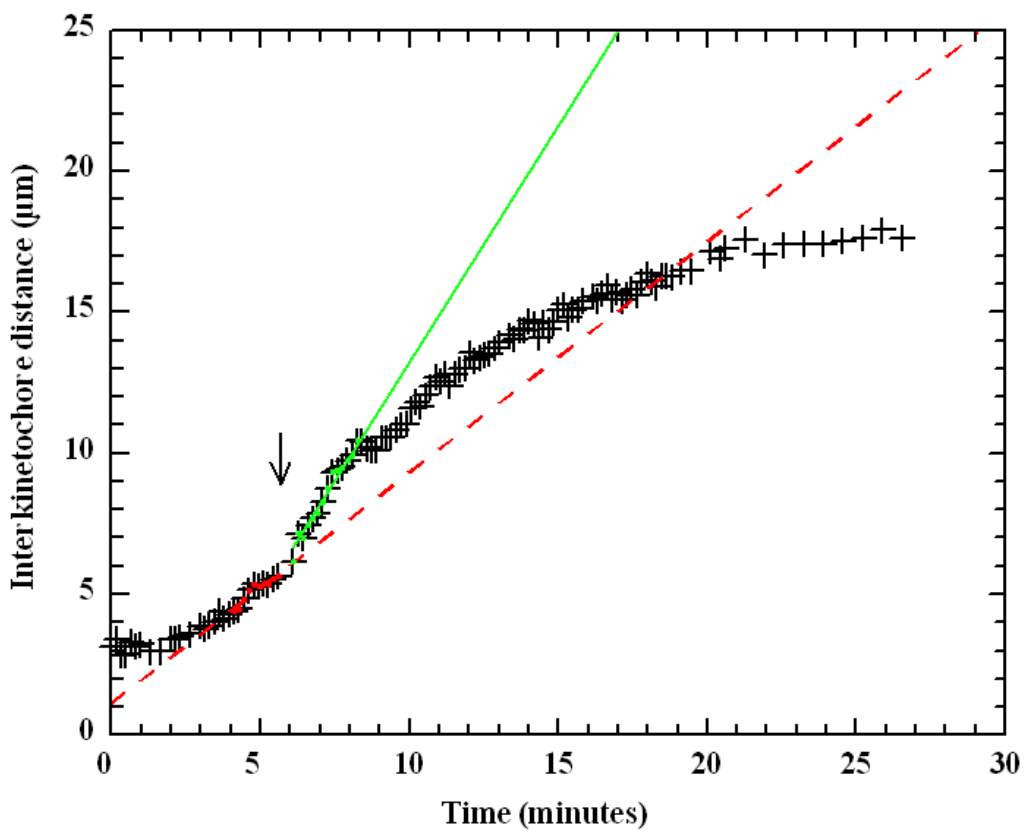


Fig. 9 - LatrunculinB

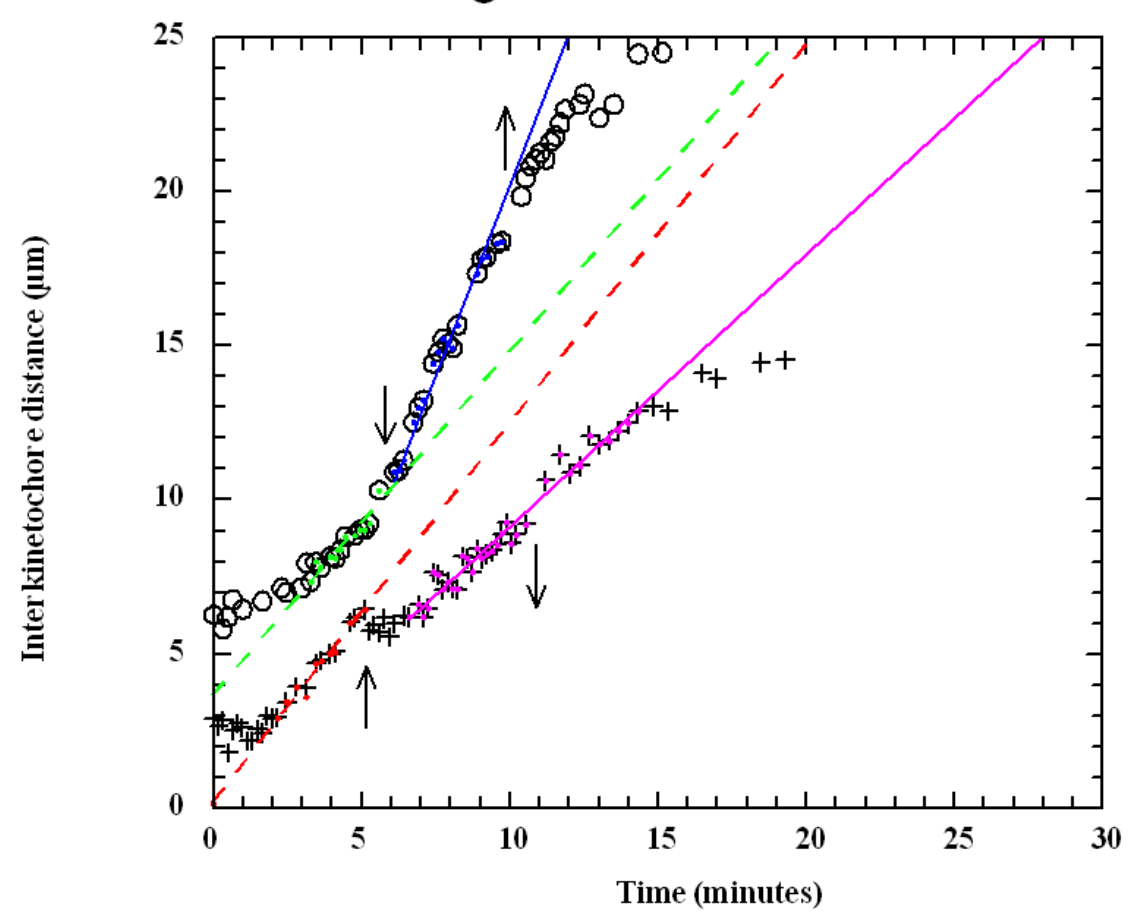

Fig. 10. Actin in LatB treated cells

Actin

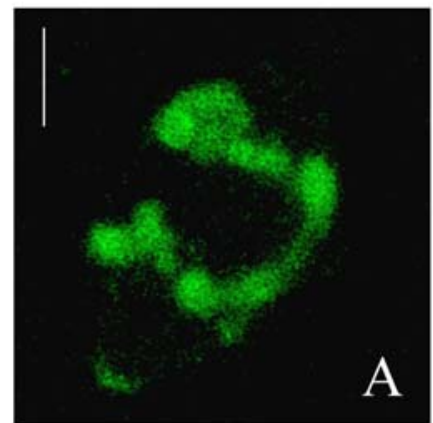

DIC

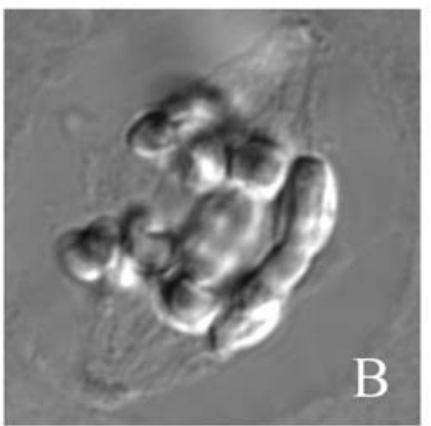


Fig. 11. Gap in acetylation

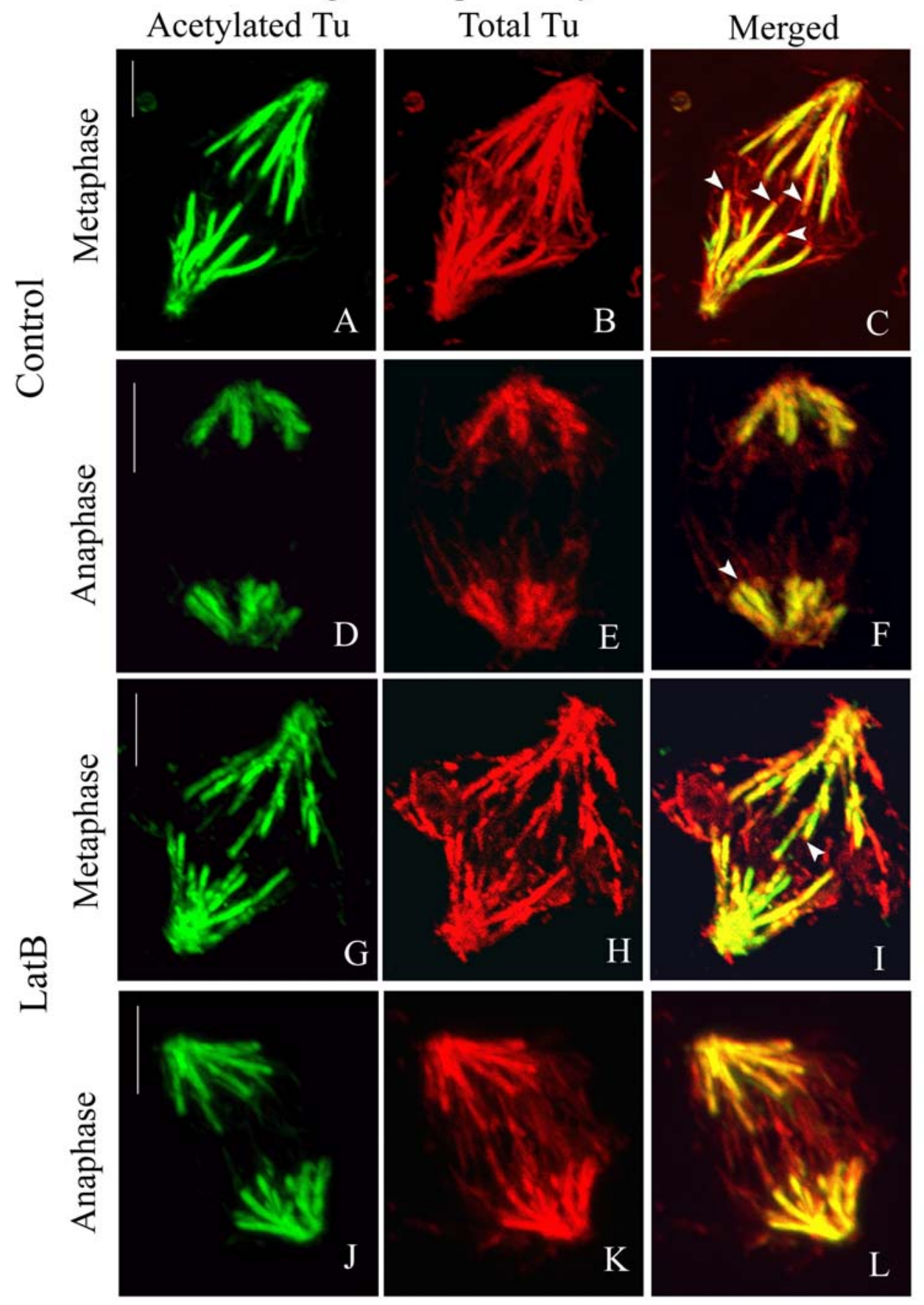


Figure 12. Gap in acetylation

A

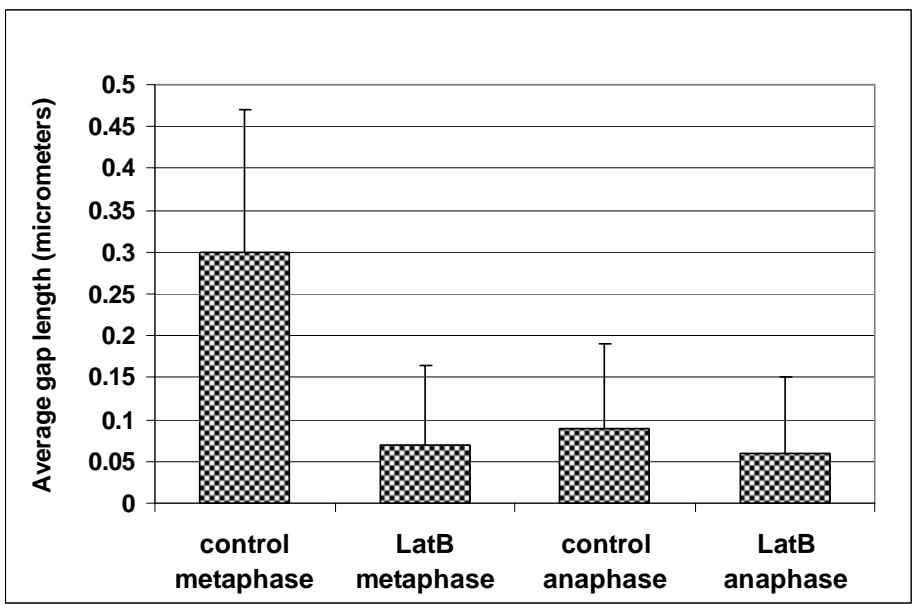

B

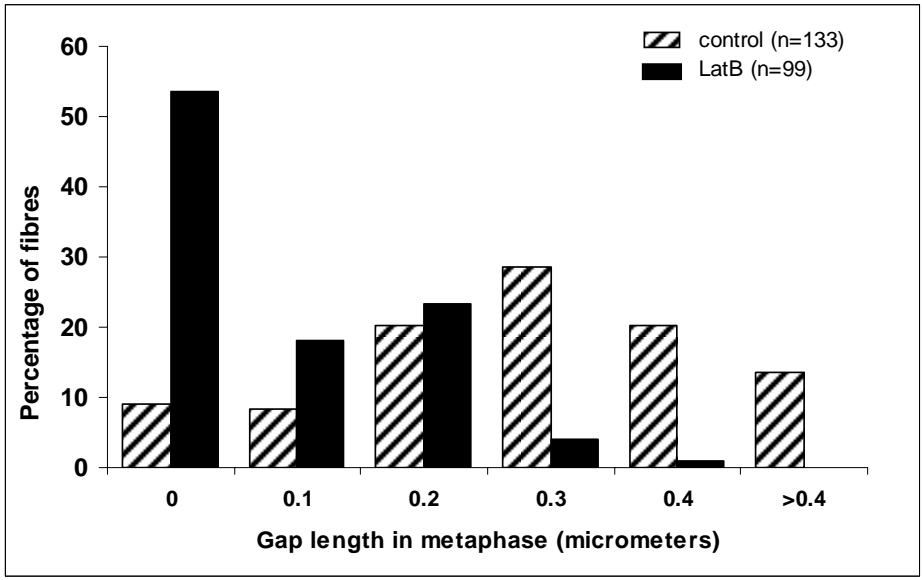

C

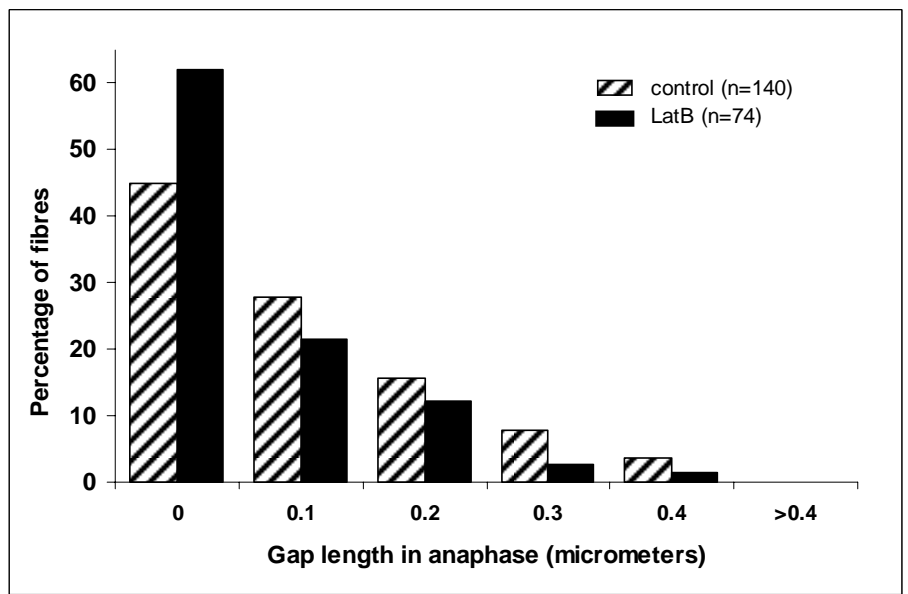

